See Article page 79.

\section{Commentary: Diffuse supravalvar aortic stenosis: Is the enemy of good always better?}

\author{
Sunil P. Malhotra, MD
}

Supravalvar aortic stenosis (SVAS) is a rare lesion associated with elastin arteriopathies that may either be familial, as in the case of Williams-Beuren syndrome, or sporadic. The classic presentation is a discrete, hourglass-appearing narrowing at the sinotubular junction. A less common, diffuse variant is observed in $16 \%$ to $30 \%$ of larger series and can have varying involvement of the ascending aorta, the aortic arch, and, in rare cases, the descending aorta. ${ }^{1,2}$ Occasionally, discrete arch vessel stenoses may be present. In this issue of the Journal, Katahira and colleagues ${ }^{3}$ report the surgical management of an adult with Williams-Beuren syndrome presenting with symptomatic severe aortic valve stenosis who had previously undergone surgical repair for localized SVAS in childhood. Preoperative workup identified diffuse SVAS involving the entire ascending aorta, with a separate proximal stenosis of the brachiocephalic artery.

Although combined aortic valve replacement and ascending aorta and hemiarch replacement is certainly not a novel surgical approach, the late presentation of progressive diffuse ascending aortic stenosis following childhood repair of discrete SVAS is highly unusual. More likely, this patient had diffuse supravalvar aortic stenosis, which manifested most severely at the sinotubular junction. Unfortunately, no information is provided in the case report that

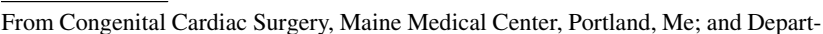
ment of Surgery, Tufts University School of Medicine, Boston, Mass.

Disclosures: The author reported no conflicts of interest.

The Journal policy requires editors and reviewers to disclose conflicts of interest and to decline handling or reviewing manuscripts for which they may have a conflict of interest. The editors and reviewers of this article have no conflicts of interest.

Received for publication Jan 16, 2020; accepted for publication Feb 2, 2020; available ahead of print Feb 20, 2020.

Address for reprints: Sunil P. Malhotra, MD, Congenital Cardiac Surgery, Maine Medical Center, 22 Bramhall St, Portland, ME 0410 (E-mail: smalhotra@mmc. org).

JTCVS Techniques 2020;3:85-6

2666-2507

Copyright (C) 2020 The Authors. Published by Elsevier Inc. on behalf of The American Association for Thoracic Surgery. This is an open access article under the CC BY-NCND license (http://creativecommons.org/licenses/by-nc-nd/4.0/).

https://doi.org/10.1016/j.xjtc.2020.02.006
}

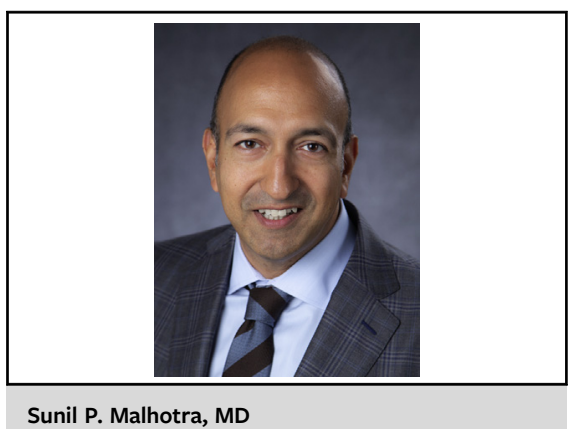

CENTRAL MESSAGE

Surgical decision-making in

diffuse supravalvar aortic steno-

sis is discussed.

comments on the degree of diffuse aortic involvement at the initial operation.

Importantly, this clinical vignette raises the following question for the surgeon: When should diffuse narrowing of the ascending aorta and/or aortic arch be addressed at the time of primary surgery for sinotubular SVAS? The obvious answer is: it depends. The degree of diffuse narrowing and extent of aortic pathology will alter the risk/ benefit calculus in surgical decision-making. Hickey and colleagues ${ }^{4}$ found all surgical reinterventions in their series were for recurrent gradients in the distal ascending aorta or beyond. However, it should be noted that several studies have demonstrated increased operative mortality risk with extensive aortic repair. ${ }^{1,5}$ The most comprehensive multicenter study of SVAS included 76 patients with diffuse-type SVAS and found that the univariate risk factors for mortality were diffuse type and age $<12$ months. ${ }^{6}$ Nonetheless, most surgeons would agree that the hemodynamic burden of moderate aortic obstruction on the left ventricle should be relieved by patch augmentation or graft replacement. Aggressively addressing significant diffuse supravalvar stenosis at the initial surgical repair will result in a sustained improvement in hemodynamics and reduce the need for future reoperation.

\section{References}

1. van Son JAM, Danielson GK, Puga FJ, Schaff HV, Rastogi A, Edwards WD, et al Supravalvar aortic stenosis: long-term results of surgical treatment. J Thorac Cardiovasc Surg. 1994;107:103-15.

2. Deo SV, Burkhary HM, Schaff HV, Li Z, Stensrud PE, Olson TM, et al. Late outcomes for surgical repair of supravalvar stenosis. Ann Thorac Surg. 2012;94 854-9. 
3. Katahira S, Sugimura Y, Lichtenberg A, Akhyari P. Late reoperation after proximal repair of supravalvular stenosis for diffuse form of Williams-Beuren syndrome. J Thorac Cardiovasc Surg Tech. 2020;3: $79-81$.

4. Hickey EJ, Jung G, Williams WC, Manlhiot C, Van Arsdell GS, Caldarone CA, et al. Congenital supravalvar aortic stenosis: defining surgical and nonsurgical outcomes. Ann Thorac Surg. 2008;86:1919-27.
5. Stamm C, Kreutzer C, Zurakowski D, Nollert G, Friehs I, Mayer JE, et al Forty-one years of surgery for congenital supravalvar aortic stenosis. J Thorac Cardiovasc Surg. 1999;118:874-85.

6. Padalino MA, Frigo AC, Comisso M, Kostolny M, Omeje I, Schreiber C, et al. Early and late outcomes after surgical repair of congenital supravalvar aortic stenosis: a European Congenital Heart Surgeons Association multicentric study. Eur J Cardiothorac Surg. 2017;52:789-97. 